\title{
Correction to: The origin, fate, and contribution of macrophages to spinal cord injury pathology
}

\author{
Lindsay M. Milich ${ }^{1} \cdot$ Christine B. Ryan ${ }^{1} \cdot$ Jae K. Lee $^{1} \mathbb{C}$
}

Published online: 22 April 2019

(c) Springer-Verlag GmbH Germany, part of Springer Nature 2019

\section{Correction to: Acta Neuropathologica}

https://doi.org/10.1007/s00401-019-01992-3

The original version of the article contains a labeling error in Fig. 2. The boxed molecular description of pro-inflammatory and anti-inflammatory macrophages were switched. $\mathrm{Ly} 6 \mathrm{C}^{\mathrm{Hi}}, \mathrm{Cx} 3 \mathrm{Cr} 1^{\mathrm{Lo}}, \mathrm{Ccr} 2^{\mathrm{Hi}}$ should have been associated with pro-inflammatory macrophages on the left, and Ly6 $\mathrm{C}^{\mathrm{Lo}}$, $\mathrm{Cx} 3 \mathrm{Cr} 1^{\mathrm{Hi}}, \mathrm{Ccr} 2^{\mathrm{Lo}}$ should have been associated with antiinflammatory macrophages on the right.

The corrected figure is given below.

The original article can be found online at https://doi.org/10.1007/ s00401-019-01992-3.

Jae K. Lee

JLee22@med.miami.edu

1 Miami Project to Cure Paralysis, Department

of Neurological Surgery, University of Miami School

of Medicine, Miami, FL 33136, USA 
Fig. 2 Schematic illustration of putative sources of macrophages after spinal cord injury. Pro-inflammatory splenic macrophages comprise the major source of the initial wave of macrophage influx. A second wave of anti-inflammatory macrophages could be from either the bone marrow or from a self-renewing source at the injury site. The spinal cord injury site is comprised of a fibrotic core comprised of nonneural cells such as fibroblasts and macrophages surrounded by neural cells such as astrocytes and microglia. Bone marrow chimera studies (Fig. 1) demonstrate the presence of $\mathrm{Cx} 3 \mathrm{Cr} 1^{\text {lo }}$ macrophages in the fibrotic region, and $\mathrm{Cx} 3 \mathrm{Cr} 1^{\text {hi }}$ macrophages in both the fibrotic and surrounding neural tissue. These two types of macrophages could correspond to the pro-inflammatory and anti-inflammatory subtypes from the spleen and bone marrow, respectively

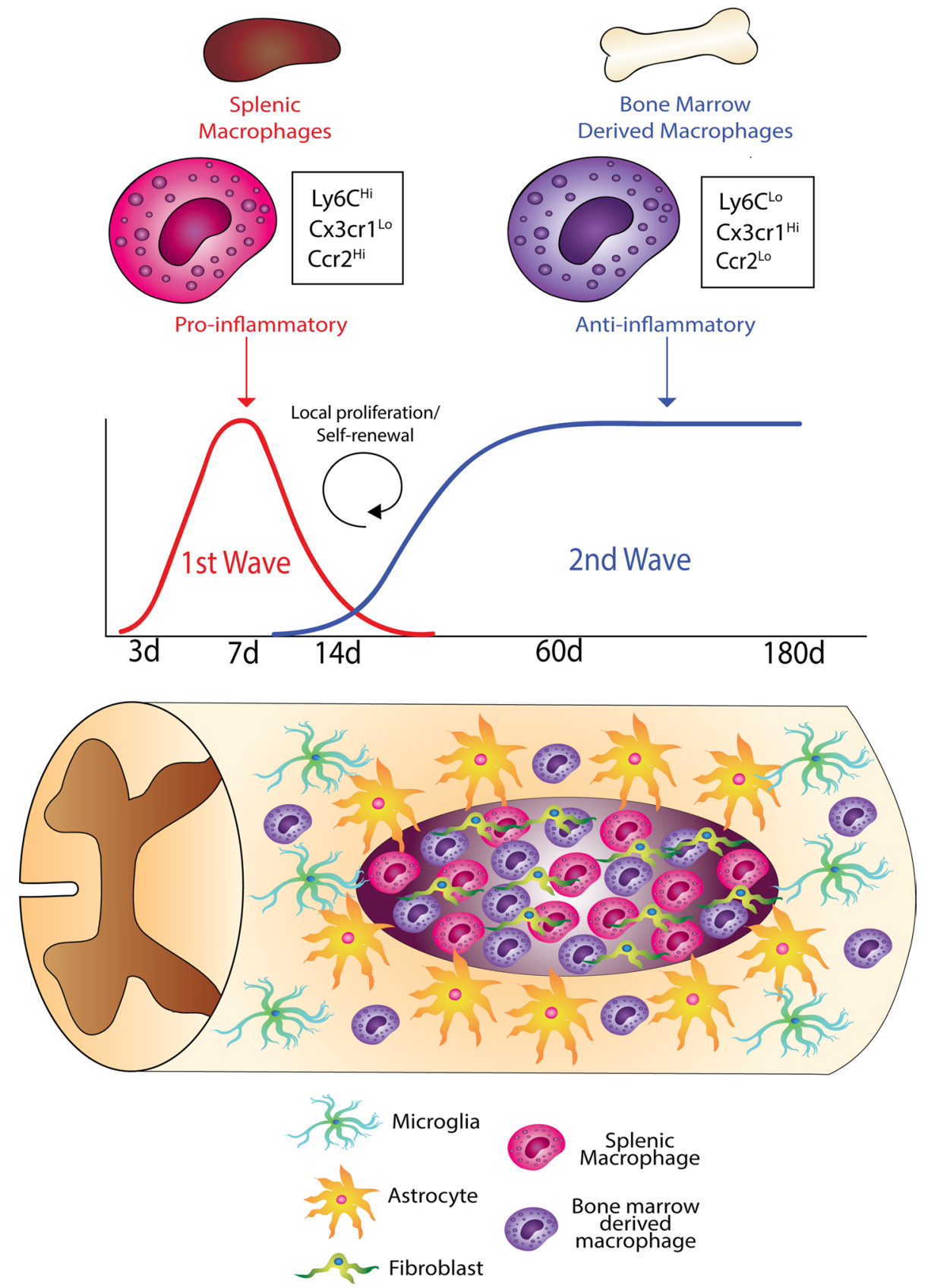

Publisher's Note Springer Nature remains neutral with regard to jurisdictional claims in published maps and institutional affiliations. 